Culture et histoire dans l'espace roman

$12 \mid 2014$

Empreintes/emprunts : entre forces de conformisation et forces d'innovation

\title{
El personaje irreal en la novela criminal contemporánea: la huella francesa
}

\section{Alejandro Pedregosa}

\section{(2) OpenEdition}

\section{Journals}

Edición electrónica

URL: https://journals.openedition.org/cher/7062

DOI: $10.4000 /$ cher.7062

ISSN: 2803-5992

\section{Editor}

Presses universitaires de Strasbourg

\section{Edición impresa}

Fecha de publicación: 7 julio 2014

Paginación: 13-19

ISBN: 978-2-86820-569-8

ISSN: 1968-035X

\section{Referencia electrónica}

Alejandro Pedregosa, «El personaje irreal en la novela criminal contemporánea: la huella francesa», reCHERches [En línea], 12 | 2014, Publicado el 13 diciembre 2021, consultado el 15 diciembre 2021. URL: http://journals.openedition.org/cher/7062 ; DOI: https://doi.org/10.4000/cher.7062

\section{(c) (i) (2)(2)}

Ce(tte) œuvre est mise à disposition selon les termes de la Licence Creative Commons Attribution -

Pas d'Utilisation Commerciale - Partage dans les Mêmes Conditions 4.0 International. 


\title{
El personaje irreal en la novela criminal contemporánea: la huella francesa
}

\author{
Alejandro Pedregosa \\ Romencier
}

Intentaré exponer, a lo largo de las siguientes páginas, las principales huellas, los rastros fundamentales y las impagables deudas que algunos autores han ido dejando en mi trabajo como escritor de novelas criminales.

En todos ellos hay un hilo invisible y común del que también yo he pretendido tirar a la hora de imaginar algunas de mis novelas: la irrealidad. La irrealidad es un fenómeno que, sin ser una rareza, no resulta, desde luego, el elemento más común en las novelas criminales, pues si de algo se siente orgulloso este género es precisamente de ser uno de los paladines del realismo contemporáneo.

No pretendo, en modo alguno, limitar los grandes logros que el «realismo» ha aportado al género. De hecho, dedicaré el principio de mi intervención a destacar la importancia del fenómeno realista en la construcción de lo criminal. Sin embargo, considero que el paso de los años, el éxito editorial de una fórmula predefinida y, en ocasiones, una labor crítica bastante acomodaticia han hecho que buena parte de la producción criminal se autoimpusiera una especie de tiranía realista que en sus peores versiones ha tendido a la redundancia, la monotonía y la tibieza literaria.

No parece muy sensato empezar esta conferencia tirando piedras contra mi propio tejado, y de paso, arriesgarme a polemizar con los colegas, algo que realmente está muy lejos de mi interés. Pero nos encontramos en una facultad de literatura, y aquí no podemos engañarnos: el realismo, per se, no es una cualidad literaria. Para escribir una buena novela criminal no basta

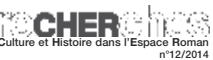


con desarrollar una trama ingeniosa, ni despacharse con dolorosísimos ejemplos de la crueldad humana; ambas cosas pueden ayudar, pero no bastan. Para hacer una buena novela criminal, al igual que cualquier otro tipo de novela, tan solo es necesario una cosa. Una única cosa: escribirla bien. Es decir, someter a todos los elementos que conforman una historia criminal a los rigores del sentido literario. Ese concepto tan útil como inaprensible que los teóricos denominan: literariedad.

Así, bajo mi punto de vista, la aparición en estas novelas de aspectos «irreales» no supone demérito alguno, siempre, claro está, que obedezcan a una realidad superior, la realidad literaria o literariedad; la única capaz de separar lo pertinente de lo que no lo es. Cabe señalar en este punto que no conviene confundir la «realidad literaria» con la verosimilitud, pues, aunque en lo tocante a lo criminal, son conceptos cercanos, esta atiende a criterios internos de funcionalidad, mientras que aquella responde a criterios estéticos de orden más general.

Pero ya está bien de pirotecnia teórica. Vayamos al grano. Si pretendo defender la incursión de «lo irreal» en el género habrá que recordar primero cómo fue la fundación de lo real, qué periplo ha seguido este concepto y por qué ha llegado a ser hoy día su más fiel aliado.

En 1944 Raymond Chandler dejó escrito un decálogo (The simple art of murder) en el que consignaba los diez mandamientos fundamentales de la novela negra; un género que él, con su sagacidad literaria, ayudó a encumbrar definitivamente. El tercero de los puntos decía: «Los personajes, el ambiente y la atmósfera deben ser realistas. Hay que hablar de personas reales en un mundo real».

Con semejante aserto apuntalaba la novela negra y daba por superado lo que podíamos definir como «la etapa de los grandes enigmas», donde hasta hacía bien poco, Sherlock Holmes, Hércules Poirot o la bondadosa Señorita Marple habían brillado con una luz tan amable como entretenida.

¿De qué hablaba Chandler cuando hablaba de realismo? ¿Acaso hasta entonces las novelas de intriga criminal no habían sido realistas? Quizá convenga detenerse un instante en estas dos cuestiones.

Las novelas de intriga surgidas, en sus diferentes versiones, a partir de Los crímenes de la calle Morgue tienen, según entiendo, no pocas dosis de realismo; baste recordar las maravillosas ambientaciones acaecidas en las zonas rurales británicas, donde Connan Doyle, Chesterton o Agatha Christie pusieron a trabajar a sus detectives, los cuales, al tiempo que descubrían 
al asesino con deslumbrantes argumentos de corte racional e incluso psicológico, aprovechaban para recrear los usos de un lugar (a menudo pueblo) o de una clase social (a menudo alta).

Se podría decir que el realismo de esta época afecta sobre todo al decorado, al armazón que sostiene la intriga. Sería pues un realismo amablemente costumbrista, pero realismo a fin y al cabo.

Sin embargo, lo que Chandler demanda no son decorados realistas sino, literalmente, "personajes reales en un mundo real», y eso es algo muy distinto, algo que afecta a los niveles fundamentales de la narratividad y, por lo tanto, al tipo de artefacto literario que se quiere construir.

Para no abundar en aspectos ya sobradamente conocidos diré que el realismo que Chandler inaugura en los Estados Unidos, junto a figuras como Dashell Hammett o Jim Thompsom, se fundamenta en tres pilares que la novelística criminal anterior no explota: por un lado, la ciudad, como escenario polimorfo en el que conviven la miseria y la abundancia; por otro, la violencia, ejercida en todas sus direcciones (del centro a la periferia y viceversa); y finalmente la maleabilidad del sistema democrático capitalista; y señalo la doble naturaleza «democrático-capitalista», porque es en esa dualidad donde la novela criminal inaugura, antes incluso del descrédito humanista que supondrá la Segunda Guerra Mundial, una de las mayores ironías posmodernas: aquella que muestra la falibilidad de los grandes discursos.

Estos tres pilares, ciudad, violencia y descrédito del sistema se funden, como en una santísima trinidad, en un único concepto que dio en denominarse Hard boiled (algo que podríamos traducir por «pura ebullición»). Es aquí cuando la literatura criminal alcanza su máxima temperatura, su mayoría de edad, y se lanza a contar las cosas tal y como son.

Por lo tanto, no cabe negar ni un ápice de importancia a los clásicos de la novela criminal, y mucho menos al valor fundamental que su idea de «realidad» cumple en la literatura del momento. Tal y como ocurrió con Balzac, algunas novelas de Chandler explican el contexto social en el que transcurren mejor que muchos libros de Historia. Si además, lo hacen con incontestables valores literarios, no hay nada más que añadir, tan solo celebrar: estamos ante un grande cuyo uso del «realismo» entroniza un género.

Y vamos a detenernos ahí, en el valor literario, en las capacidades artísticas de los textos criminales, porque es en este punto donde mi experiencia 
lectora me dice que los elementos «irreales», sobre todo los que afectan a los personajes, posibilitan la ampliación del género, el ensanchamiento de horizontes y la incursión en terrenos mestizos como la literatura de humor o de terror.

Voy a utilizar tres ejemplos que considero paradigmáticos del buen hacer que la irrealidad tiene en los textos criminales. Tres ejemplos que distan mucho en sus intenciones artísticas y, sin embargo, consiguen resolver las problemáticas irreales que plantean sin menoscabar ni uno solo de los rigores propios de una trama criminal.

Por un lado, el español Eduardo Mendoza y su mítico detective Celedonio; por otro, la francesa Fred Vargas con su panoplia de personajes imposibles; y finalmente el irlandés John Connoly, donde la irrealidad adquiere tintes paranormales.

Eduardo Mendoza es un escritor amplio, de profundo calado tanto en la crítica española como en el público. Dos de sus novelas, El misterio de la cripta embrujada y El laberinto de las aceitunas, encumbraron a Celedonio, un detective absolutamente irreal e hilarante al que el propio Mendoza presenta con estas palabras: «es un individuo de la más baja extracción social, cuya carrera delictiva y una sucesión de accidentes que nunca me entretuve en relatar (ni siquiera en imaginar) han arrojado a un manicomio, del que un policía venal, el comisario Flores, le hace salir para que le ayude a resolver un misterio. El planteamiento es tan absurdo que permite cualquier atentado contra las normas del realismo, e incluso de la verosimilitud, como por ejemplo que sea el propio detective loco quien cuente su aventura en un estilo heterodoxo, vulgar y culterano. Huelga decir que se trata de un relato humorístico, remotamente emparentado con la literatura picaresca y el esperpento».

Me detengo en dos aspectos. El primero a nivel argumental, lo que Mendoza considera un «atentado contra las normas del realismo»; y en segundo lugar, otro atentado en el nivel discursivo del texto, pues Celedonio, que narra en primera persona, lo hace de una manera «heterodoxa, vulgar y culterana». Es decir, el protagonista está contando una historia delirante con el lenguaje de un chiflado miserable que salpica su discurso de extraños barroquismos para simular una cultura que no tiene.

En definitiva, Mendoza con su doble atentado (argumental y discursivo) hace saltar por los aires el sacrosanto mandamiento que en su día inaugurara Chandler: «hablar de personas reales en un mundo real». Pues bien, 
Celedonio es un personaje irreal en una Barcelona irreal, y para más inri, se expresa de una manera absolutamente irreal. La quiebra pues está servida.

Sin embargo, hay un último detalle que Mendoza nos señala: el carácter picaresco y esperpéntico de sus novelas; y es en este punto, donde la literatura de Mendoza se reúne con la de Chandler y con la de todos los grandes novelistas del género. Porque, ¿qué es la picaresca sino el dibujo mordaz y ligeramente triste de una realidad concreta? ¿Qué es sino un ejercicio de realismo pasado por el tamiz de la ironía? La picaresca. Quizá sea esta la mejor y más grande aportación que la literatura española haya hecho al género criminal.

Estoy saturado de leer en reseñas y en entrevistas promocionales el importante papel que la novela negra realista juega hoy día a la hora de explicar un mundo en crisis, donde la voracidad criminal de unos pocos propicia el sufrimiento de millones de personas, cuando no, directamente, el desmantelamiento de unos sistemas sociales basados en el humanismo y la solidaridad. Todavía no he leído (no digo que no las haya o que no vayan a llegar) una sola de esas novelas negras realistas y pretendidamente "críticas», donde la vulnerabilidad de los débiles, la denuncia de los agresores y las paradojas criminales se pongan de manifiesto de una manera tan clara como en las novelas de Mendoza. Otra cosa es que el corazón no se te sobrecoja o la indignación no te arrebate, porque precisamente ese es el puente que la irrealidad propicia; el puente del distanciamiento que te hace, una vez terminada la risa, entender el problema de una manera global.

El segundo de los ejemplos, (se anuncia en el subtítulo de esta conferencia como «la huella francesa»), tiene a la escritora Fred Vargas por protagonista. Mi profunda ignorancia de la lengua francesa (algo que empezaré a corregir más pronto que tarde) me impide valorar de un modo crítico los logros discursivos de estas novelas. Las traducciones al español no son uniformes, $y$ si bien me he encontrado con libros de verdadero interés como Sin hogar ni lugar (Sans feu ni lieu, 1997), El hombre del revés (L'homme à l'envers, 1999) o El ejército furioso (L'Armée furieuse, 2011), también he advertido en otras traducciones ciertos desajustes que me ofrecen las lógicas dudas.

Estoy hablando del nivel discursivo, porque lo que supera con creces cualquier posible traducción, es el indiscutible talento de Fred Vargas para construir personajes. En un fugaz repaso por su biografía encontramos a Louis Khelweiler, un husmeador profesional que anda siempre con un sapo metido en el bolsillo del abrigo; a los denominados tres evangelistas, tres amigos estudiantes de Historia cada uno excéntrico y brillante a su manera, 
que se reparten las plantas del viejo caserón desvencijado en el que viven en un estricto orden histórico: la planta baja para el pre-historiador, la primera para el medievalista, y la tercera para Lucien, un obseso de la primera guerra mundial. O qué decir de la familia Vandermot donde la hija sufre de aterradoras visiones, el hermano mayor habla al revés y el menor tiene los huesos de arcilla. Y se podría seguir añadiendo ejemplos tan «irreales» como bien construidos. Decía un escritor y crítico español, José María Mendiluce, que a los personajes de Fred Vargas no daban ganas de leerlos sino de llevártelos a casa para vivir con ellos. Comparto fieramente esta opinión, y quiero señalar un detalle que me parece ha pasado desapercibido cuando se habla de la autora francesa, y que a mi modesto entender es lo que la hace merecedora de un lugar especial en la novelística policíaca contemporánea: todos los personajes irreales de Vargas están siempre al servicio de una suerte de optimismo humanista inusual en este tipo de novelas, donde a menudo, priva la desesperanza y el desasosiego vital. Yo me enamoré literalmente de ese cuidado que Fred Vargas pone en los personajes débiles, en los excluidos, a los que convierte en irreales precisamente para dotarlos de algún tipo de fortaleza que les haga resistir los envites de la vida.

La protección del desamparado es una constante silenciosa en las novelas de Fred Vargas. El perseguido por la ley, el presunto criminal siempre encuentra un cobijo humano donde ocultarse en espera de poder demostrar su inocencia. Si los fallos en los sistemas sociales provocan asesinatos, los personajes de Vargas pertenecen a un sistema superior, el de la piedad humana, aquel que fía toda su fortuna a su confianza en el otro, en el amigo, en el débil, en el perseguido.

El tercero de los casos a comentar es John Connolly, un escritor irlandés que ambienta sus novelas en la costa este de los EE.UU. Su detective, Charlie Parker, cumple escrupulosamente el perfil del detective clásico americano, sin embargo, el mundo en el que se mueve está repleto de aspectos irreales, empezando por los espectros de su hija y de su primera mujer que fueron cruelmente asesinadas y que a menudo se le aparecen. De este modo, la irrealidad se entronca aquí con lo fantasmagórico y con el más allá. La muerte, eje fundamental de la novela criminal, tiene una doble cara en Connoly, la real (sanguinaria, inclemente, pavorosa) y la irreal (donde viven los muertos) que a menudo se presenta para socavar el día a día de los vivos y que, en lo narrativo, funciona como oculto motor de los acontecimientos.

Así, si en Fred Vargas o en Mendoza (en toda la novela mediterránea) el crimen es apenas un pretexto para que la novela pueda darse, en Connolly 
la maldad es una presencia constante, ancestral y demoníaca que persigue a Charlie Parker sin que él sepa muy bien por qué. Hay en Connoly pretendidos guiños a la novela de terror, creando momentos de verdadera tensión narrativa y dramática. Momentos de angustia $\mathrm{y}$, a qué negarlo, instantes en que te sientes demasiado solo en casa y acabas por cerrar el libro por temor a que aparezcan entre las sombras algunos de esos demonios en los que nunca has creído pero en que las páginas de Connolly cobran una incomprensible realidad.

«Los malos» de Connolly son una especie de ángeles caídos y eternos que se renuevan en cada libro y que siempre vienen en su búsqueda, para renovar la eterna lucha del bien contra el mal. Cierto que sus mejores amigos, Louise y Ángel son asesinos profesionales y no tienen reparo en matar a cuanto estorbo se les ponga por delante; sin embargo, son agentes del bien, en tanto que ayudan a Charlie a salir de sus constantes infiernos.

Pero más allá del mal rotundo y de la fantasmagórica irrealidad que trufa sus novelas, lo principal en Connolly es, sin duda, su elegancia narrativa, el lirismo sutil que ilumina su prosa, y que yo les recomiendo vivamente en títulos como Los amantes (The Lovers, 2009), Perfil asesino (The Kiling Kind, 2001) o Todo lo que muere (Every Dead Thing, 1999).

En definitiva, y a modo de resumen, he intentado poner el foco de atención en las tres huellas narrativas que considero forman una parte innegable de mis novelas criminales. De un lado el humor (Mendoza) como forma de desmontar la realidad con el premeditado interés de repensarla y analizarla; en segundo lugar la humanidad militante de los personajes (Vargas), que tiene mucho que ver, en el fondo, con una perspectiva optimista de estar en el mundo; y finalmente, el lirismo dramático de la prosa de Connolly, que entronca, quizá, con mis raíces poéticas y con el gusto por colocar la palabra justa en el lugar apropiado. 